\title{
Effect of Organic Soil Amendments on Establishment Vigor, Seedling Emergence, and Top Growth in Kentucky Bluegrass
}

\author{
Kyoung-Nam Kim ${ }^{*}$ \\ Department of Horticulture, College of Science and Technology, Sahmyook University, Seoul 139-742, Korea
}

\begin{abstract}
Due to limited supplies and expensive importing costs, it is a goal to replace overseas peat with local soil amendments in turf industry of Korea. The study was initiated to compare the performances of five domestic and imported organic soil amendments (OSAs) on establishment characteristics and to provide basic information for root zone composition on sports turf design and construction. The study was conducted in Kentucky bluegrass (Poa pratensis L., KB) under greenhouse conditions from March to June in 2008. A total of 25 treatments of OSA + sand were prepared. These amendments were Berger Peat (OMA), Eco-Peat (OMB), G1-Soil (OMC), Premier Peat (OMD), and Supersoil I (OME). Significant differences were observed in establishment vigor, seedling emergence, and top growth. Results varied depending upon the type of OSAs and their rates in rootzone mixtures. OMA reached over $70 \%$ in establishment vigor in 5 WAS (weeks after seeding). OMC produced a maximum vigor of approximately $60 \%$ in 6 WAS. The OME amendment, however, showed poor performance lower than $30 \%$ in establishing KB turf until 8 WAS. There were considerable variations of top growth, being 3.8 to $14.5 \mathrm{~cm}$. Greater differences in top growth resulted from OME mixtures. Shoot growth orientation in KB is also influenced by OSAs. In general, optimum mixing rate was considered as 10 to $20 \%$ for establishment vigor and 20 to $40 \%$ for top growth. Considering overall responses to establishment vigor, seedling emergence, and shoot growth, both local OMC and overseas OMD are considered as the useful soil amendments applicable for sports turfs. Domestic OME amendment would be applied for a low maintenance turfs such as rough and utility areas due to greater shoot growth. Information on these amendments would be of practical use for sports turf design and construction. Repeated experiments and field performance test are required to evaluate these OSA effect on other major turfgrass species and also to determine local OSA as imported peat substitute.
\end{abstract}

Additional key words: peat, plant height, rootzone mix, turfgrass survival, vertical shoot growth

\section{Introduction}

High-quality sports turfs are rarely closed for sufficient time for turf recovery and/or for certain maintenance practices. This is true for most cases in Korea, especially in sports turf areas such as world cup soccer stadiums and private membership golf courses. They are subjected to regular watering, frequent mowing, and intense traffic (Kim, 2006; KISS, 1998). To maintain a high-quality turf under these situations is becoming a practical challenge for the Korean turf managers. If sports turfs are not properly constructed, they easily become compacted leading to declining growth, undesirable turf quality, and unacceptable playing conditions (Beard, 1973).
The quality sports turfs have been mainly established in sand soil systems to solve soil compaction issues (Cockerham, 1994; Puhalla et al., 2002). When establishing sports turfs in sandy soils, soil amendments are incorporated into rootzone mixes for golf tee, fairway and putting greens, and soccer fields. This application leads to beneficial changes in soil properties, resulting in improvements of drainage, water holding capacity, and nutrient retention (Kerek, 2003; Koh et al., 2006; Li et al., 2000; Lucas et al., 1965). Other improvements include better germination rate, higher seedling survival, and turfgrass quality enhancement.

Soil amendments are classified as two types according to the raw materials used. They may be inorganic or organic amendments (Puustjarvi and Robertson, 1975). Organic

\footnotetext{
*Comesponding author:knkturf@syu.ac.kr
}

※ Received 13 December 2012; Revised 12 June 2013; Accepted 3 July 2013. This paper was supported by the funding of Sahmyook University in 2014

(C) 2014 Korean Society for Horticultural Science 
soil amendments (OSA) have beneficial effects on improving the soil physical and chemical property (Landschoot and McNitt, 1997). It also provides suitable environment which leads to increased beneficial microorganisms (Ham et al., 1993; Puustjarvi and Robertson, 1975), disease suppression (Liu et al., 1995), increased turf growth (Kim et al., 1998) and fertilizer and organic matter substitute (Garling and Boehm, 2001; Logan and Harrison, 1995). Organic matter in soil amendments is desirable for soil structure, soil aeration, moisture movement, nutrient availability, and ecosystem sustainability (Bandaranayake et al., 2003; Kim, 2007). It is a good element in turfgrass soil system as a function of nutrient sources that need for turfgrass growth (USGA Green Section Staff, 1973).

Peat is the most common organic amendment used in turf industry around the world. It is a main organic source in high-quality turf construction of golf courses and sports fields. However, peat is a nonrenewable resource in limited supply (Liu et al., 2005; Waltz and McCarty, 2005). Also, it is very expensive due to transportation costs for importing from North America. Furthermore, it is hard to secure it at right time to meet construction schedule due to unexpected delay from customs and quarantine process. Interest in peat substitutes has been long increased in Korea. Use of composted organic materials from locally available sources is one of the feasible options, but domestic soil amendments are not used extensively due to a lack of information on their performance on soil properties and turfgrasses. Accordingly, performance tests for domestic amendments are of a great interest. Furthermore, comparison studies between local and overseas amendments are practically needed for turf industry in Korea.

Kim (2009a, 2009b) reported that domestic soil amend- ments affected the growth and quality of Kentucky bluegrass (Poa pratensis L.) and perennial ryegrass (Lolium perenne L.). In a study by Koh et al. (2006) organic amendments from local animal manure and sawdust increased the root growth and turf quality of Korean lawngrass (Zoysia japonica Steud.) and Kentucky bluegrass. Some data are also available on the growth responses in rootzone mixes of sand plus organic amendments or mineral nutrients (Choi et al., 1994; Ham et al., 1993, 1997; Kim, 2011, 2012; Kim and Park, 2011; Kim et al., 1992, 1998, 1999, 2003; Koh et al., 2006; Lee, 2003). These experiments, however, were only conducted with single soil amendment or rootzone mixture with imported peat. No previous studies have been made in comparing local amendments with overseas peats for an establishing purpose.

The objectives of this study were to evaluate both domestic and imported soil amendments on establishment vigor, seedling emergence, and top growth, to compare their performance for rootzone mixes, to determine mixing rate for each OSA, and finally to provide basic information for rootzone mixture on sports turf design and construction with these amendments.

\section{Materials and Methods}

\section{Treatments and Experimental Design}

The study was conducted in Kentucky bluegrass (KB, Poa pratensis L.) 'Blacksburg' (Turf-Seed, Inc., Hubbard, OR, USA) under greenhouse conditions from March to June in 2008. Treatments were composed of mixtures of five organic matter amendments and sand. In the experiment two imported and three domestic soil amendments were selected as organic sources for rootzone mixes. These

Table 1. Source, origin, and chemical properties of organic soil amendments used for rootzone mix in the study.

\begin{tabular}{|c|c|c|c|c|c|c|}
\hline \multirow[b]{2}{*}{ Organic soil amendment ${ }^{z}$} & \multirow[b]{2}{*}{ Source } & \multirow[b]{2}{*}{ Origin } & \multicolumn{4}{|c|}{ Chemical properties $^{\mathrm{y}}$} \\
\hline & & & $\mathrm{pH}$ & $\begin{array}{c}\mathrm{EC} \\
\left(\mathrm{dS} \cdot \mathrm{m}^{-1}\right)\end{array}$ & $\begin{array}{c}\text { CEC } \\
\left(\mathrm{me} \cdot 100 \mathrm{~g}^{-1}\right)\end{array}$ & $\begin{array}{l}\mathrm{OM} \\
(\%)\end{array}$ \\
\hline OMA & Berger Peat & Canada & 3.78 & 0.115 & 124.6 & 95.8 \\
\hline OMB & Eco-Peat & Korea & 5.40 & 3.830 & 74.8 & 90.6 \\
\hline OMC & G1-Soil & Korea & 6.13 & 2.100 & 38.3 & 66.5 \\
\hline OMD & Premier Peat & Canada & 3.60 & 0.171 & 127.6 & 94.7 \\
\hline OME & Supersoil I & Korea & 6.41 & 4.590 & 81.9 & 77.8 \\
\hline
\end{tabular}

${ }^{\mathrm{z}}$ OMA, Berger Peat (Les Tourbières Berger Ltee, Quebec, Canada); OMB, Eco-Peat (Nature \& Environment Co., Ltd., Seoul, Korea); OMC, G1-Soil (Nature \& Environment Co., Ltd., Seoul, Korea); OMD, Premier Peat (Premier Tech Horticulture, Quebec, Canada); OME, Supersoil I (Jookjoo Fertilizers, Iljuk, Kyounggi, Korea).

${ }^{\mathrm{y}} \mathrm{EC}$, electrical conductivity; CEC, cation exchange capacity; OM, organic matter. 
Table 2. A total of 25 treatments for investigating the effect of organic soil amendments on establishment vigor, seedling emergence, and top growth of Kentucky bluegrass in the study.

\begin{tabular}{|c|c|c|}
\hline $\begin{array}{l}\text { Treatment } \\
\text { No. }\end{array}$ & $\begin{array}{l}\text { Organic soil } \\
\text { amendment }^{z} \\
\text { (OSA) }\end{array}$ & $\begin{array}{l}\text { Rootzone mixture of OSA } \\
\text { and } \operatorname{sand}^{\mathrm{y}}(\%, \mathrm{v} / \mathrm{v})\end{array}$ \\
\hline 1 & OMA 10 & Berger Peat $10+$ silica sand 90 \\
\hline 2 & OMA 20 & Berger Peat $20+$ silica sand 80 \\
\hline 3 & OMA 30 & Berger Peat $30+$ silica sand 70 \\
\hline 4 & OMA 40 & Berger Peat $40+$ silica sand 60 \\
\hline 5 & OMA 50 & Berger Peat $50+$ silica sand 50 \\
\hline 6 & OMB 10 & Eco-Peat $10+$ silica sand 90 \\
\hline 7 & OMB 20 & Eco-Peat $20+$ silica sand 80 \\
\hline 8 & OMB 30 & Eco-Peat $30+$ silica sand 70 \\
\hline 9 & OMB 40 & Eco-Peat $40+$ silica sand 60 \\
\hline 10 & OMB 50 & Eco-Peat $50+$ silica sand 50 \\
\hline 11 & OMC 10 & G1-Soil $10+$ silica sand 90 \\
\hline 12 & OMC 20 & G1-Soil $20+$ silica sand 80 \\
\hline 13 & OMC 30 & G1-Soil $30+$ silica sand 70 \\
\hline 14 & OMC 40 & G1-Soil $40+$ silica sand 60 \\
\hline 15 & OMC 50 & G1-Soil $50+$ silica sand 50 \\
\hline 16 & OMD 10 & Premier Peat $10+$ silica sand 90 \\
\hline 17 & OMD 20 & Premier Peat $20+$ silica sand 80 \\
\hline 18 & OMD 30 & Premier Peat $30+$ silica sand 70 \\
\hline 19 & OMD 40 & Premier Peat $40+$ silica sand 60 \\
\hline 20 & OMD 50 & Premier Peat $50+$ silica sand 50 \\
\hline 21 & OME 10 & Supersoil I $10+$ silica sand 90 \\
\hline 22 & OME 20 & Supersoil I $20+$ silica sand 80 \\
\hline 23 & OME 30 & Supersoil I $30+$ silica sand 70 \\
\hline 24 & OME 40 & Supersoil I $40+$ silica sand 60 \\
\hline 25 & OME 50 & Supersoil I $50+$ silica sand 50 \\
\hline
\end{tabular}

${ }^{\mathrm{z}} \mathrm{OMA}$, Berger Peat (Les Tourbières Berger Ltee, Quebec, Canada); OMB, Eco-Peat (Nature \& Environment Co., Ltd., Seoul, Korea); OMC, G1-Soil (Nature \& Environment Co., Ltd., Seoul, Korea); OMD, Premier Peat (Premier Tech Horticulture, Quebec, Canada); OME, Supersoil I (Jookjoo Fertilizers, Iljuk, Kyounggi, Korea). ${ }^{\mathrm{y}}$ Sand, pure silica sand meeting USGA recommendations in Table 3, which consists of sand over $90 \%$ between 0.15 and $1.0 \mathrm{~mm}$ in particle size. amendments were OMA (Berger Peat: Les Tourbières Berger Ltee, Quebec, Canada), OMB (Eco-Peat: Nature \& Environment Co. Ltd., Seoul, Korea), OMC (G1-Soil: Nature \& Environment Co. Ltd., Seoul, Korea), OMD (Premier Peat: Premier Tech Horticulture, Quebec, Canada), and OME (Supersoil I: Jookjoo Fertilizers, Iljuk, Kyounggi, Korea). Information on their source, origin, and chemical properties were described in Table 1.

Treatments were arranged with these five amendments at five volume percentages $(10,20,30,40$, and $50 \%$; v/v). The remaining soil for each treatment was sand. Accordingly, a total of 25 treatments were prepared in the study (Table 2). Pure silica sand meeting USGA putting green specifications was used (Table 3). All treatments were placed in plot with a $0.2 \mathrm{~m} \times 0.2 \mathrm{~m}\left(0.04 \mathrm{~m}^{2}\right.$ surface area). A randomized complete block design was used with six replications.

At a seeding rate of $12 \mathrm{~g} \cdot \mathrm{m}^{-2} \mathrm{~KB}$ seeds were sown in plots. It has been extensively used for residential and sports turf areas in Korea since the 2002 Korea/Japan FIFA World Cup Soccer (KOWOC, 2000). A preliminary germination test was carried out in order to use a good germination of KB cultivar. Such cultivars as 'Award', 'Blacksburg', 'Excursion', and 'Midnight' were tested with 4 replications under a controlled incubator. Alternative conditions was applied, consisting of $8 \mathrm{~h}$ light at $25^{\circ} \mathrm{C}$ and $16 \mathrm{~h}$ dark at $15^{\circ} \mathrm{C}$ (The Lawn Institute, 1991). The cultivar 'Blacksburg' was selected after one-month test, based on over $90 \%$ germination rate.

Turf was grown under greenhouse conditions with day/ night temperatures of approximately $30 / 15^{\circ} \mathrm{C}$. Water was applied as needed to prevent drought stress. The turf was unmown during the study. Whole plots were topdressed with straight silica sand and treated with fungicide on a curative basis.

\section{Measurements and Data Analysis}

Data were collected on establishment vigor, seedling emergence, and top growth. Seedling emergence was weekly investigated for 8 weeks and described as a cumulative pattern. At the end of study establishment vigor was deter-

Table 3. Particle size distribution of silica sand used for rootzone mix with organic soil amendments in the study.

\begin{tabular}{|c|c|c|c|c|c|c|c|c|}
\hline \multirow{2}{*}{$\begin{array}{l}\text { Particle size } \\
(\mathrm{mm})\end{array}$} & \multicolumn{8}{|c|}{ Particle size distribution (\%) } \\
\hline & $\begin{array}{c}\text { Gravel } \\
(2.0-3.4)\end{array}$ & $\begin{array}{c}\text { Very coarse } \\
(1.0-2.0)\end{array}$ & $\begin{array}{c}\text { Coarse } \\
(0.5-1.0)\end{array}$ & $\begin{array}{c}\text { Medium } \\
(0.25-0.5)\end{array}$ & $\begin{array}{c}\text { Fine } \\
(0.15-0.25)\end{array}$ & $\begin{array}{l}\text { Very fine } \\
(0.05-0.15)\end{array}$ & $\begin{array}{c}\text { Silt } \\
(0.002-0.05)\end{array}$ & $\begin{array}{c}\text { Clay } \\
(<0.002)\end{array}$ \\
\hline USGA $^{z}$ Spec. & $\leq 3 \%$ & $\leq 7 \%$ & \multicolumn{2}{|c|}{$\geq 60 \%$} & $\leq 20 \%$ & $\leq 5 \%$ & $\leq 5 \%$ & $\leq 3 \%$ \\
\hline Sand & 1.00 & 2.25 & \multicolumn{2}{|c|}{87.00} & 7.00 & 1.50 & 0.25 & 0.04 \\
\hline
\end{tabular}

${ }^{\mathrm{z} U S G A}$, United States Golf Association. 
mined as the number of seedlings. Top growth was also evaluated as plant height with six subsamples per replication. An analysis of variance was performed for data for treatments using the General Linear Model procedures and the Statistical Analysis System (SAS Inst., Inc., 2001). Mean separation was made with Duncan's multiple range test at $P \leq 0.05$ to detect differences among treatments (Steel and Torrie, 1980).

\section{Results and Discussion}

\section{Establishment Vigor}

Significant differences were observed in establishment vigor, seedling emergence, and top growth. Results varied depending upon the type of OSAs and their rate in rootzone mixtures. Data for turfgrass establishment vigor were described in Fig. 1. At the end of study the overall establishment vigor ranged between 3.0 and $73.3 \%$. The OMA mixtures (Treatments 1 to 5) had establishment vigor of 35.3 to $73.3 \%$. The greatest vigor of $73.3 \%$ was observed from plots in OMA 10. But the lowest value of $35.3 \%$ was also observed from the OMA 40 mixture. Treatments 6 to 10 with OMB produced 40.3 to $53.0 \%$ in establishment vigor. The highest ratings were 53.0 and $52.3 \%$ from plots in OMB 10 and OMB 20 mixtures, respectively. But the lowest vigor was $40.3 \%$ which was associated with OMB 50 .

In plots of OMC mixtures (Treatments 11 to 15), the vigor varied between 34.7 and $59.0 \%$. The greatest vigor of $59.0 \%$ was from the OMC 10 , whereas the lowest was $34.7 \%$ from the OMC 50 . Treatments 16 to 20 with OMD mixtures had a range of 17.0 to $49.3 \%$ in establishment vigor. The highest was $49.3 \%$, which was associated with the OMD 10. But the lowest was $17.0 \%$ from plots in OMD 50 mixture. From the OME plots (Treatments 21 to 25), establishment vigor ranged from 3.0 to $30.7 \%$. Both OME 10 and 20 mixtures produced the greatest vigor of 29.0 to $30.7 \%$. The lowest value of $3.0 \%$ was observed in plots of OMD 50

These results indicated the establishment vigor in KB differed with OSAs and their rate in rootzone mixes. Also, the establishment trend was weekly evaluated as seedling emergence and described as a cumulative pattern (Fig. 2). The pattern greatly varied according to the type of OSAs with time after seeding. Among five OSAs tested, overseas OMA was regarded as the most effective one, reaching over $70 \%$ of establishment vigor at OMA 10 just in 5 WAS. Domestic OMC was also a good soil amendment, producing a maximum vigor of approximately $60 \%$ at OMC 10 in 6 WAS. However, the OME amendment showed poor performance lower than 30\% in establishing KB turf until 8 WAS.

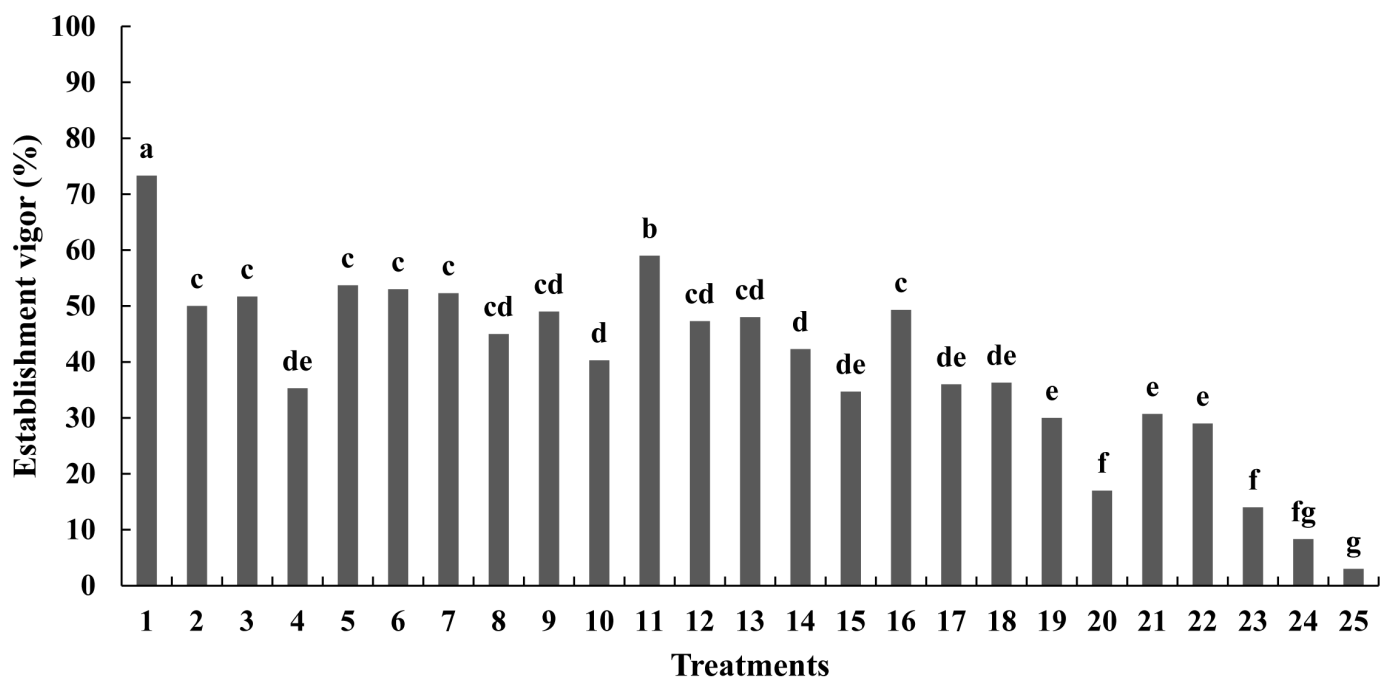

Fig. 1. Establishment vigor of Kentucky bluegrass at the end of study which was grown under greenhouse conditions. Treatments were comprised of five organic matter amendments and sand. The amendments were OMA (Berger Peat: Les Tourbières Berger Ltee, Quebec, Canada), OMB (Eco-Peat: Nature \& Environment Co., Ltd., Seoul, Korea), OMC (G1-Soil: Nature \& Environment Co., Ltd., Seoul, Korea), OMD (Premier Peat: Premier Tech Horticulture, Quebec, Canada), and OME (Supersoil I: Jookjoo Fertilizers, Iljuk, Kyounggi, Korea). A total of 25 treatments were arranged with these amendments at five volume percentages (10, 20, 30, 40, and 50\%; v/v) as described in Table 2. The remaining soil for each treatment was a pure silica sand meeting USGA putting green specifications. Bars with different letters are significantly different based on Duncan's multiple range test at $P=0.05$. 
Other amendments, OMB and OMD, had an intermediate rate of establishment vigor, producing $50 \%$ or so in 8 WAS.

For the best rootzone mix, the optimum rate was variable with OSA in the study. In general, 10 to $20 \%$ could be recommended for fast establishment vigor. Higher rates over $40 \%$ resulted in very poor establishment. It has been
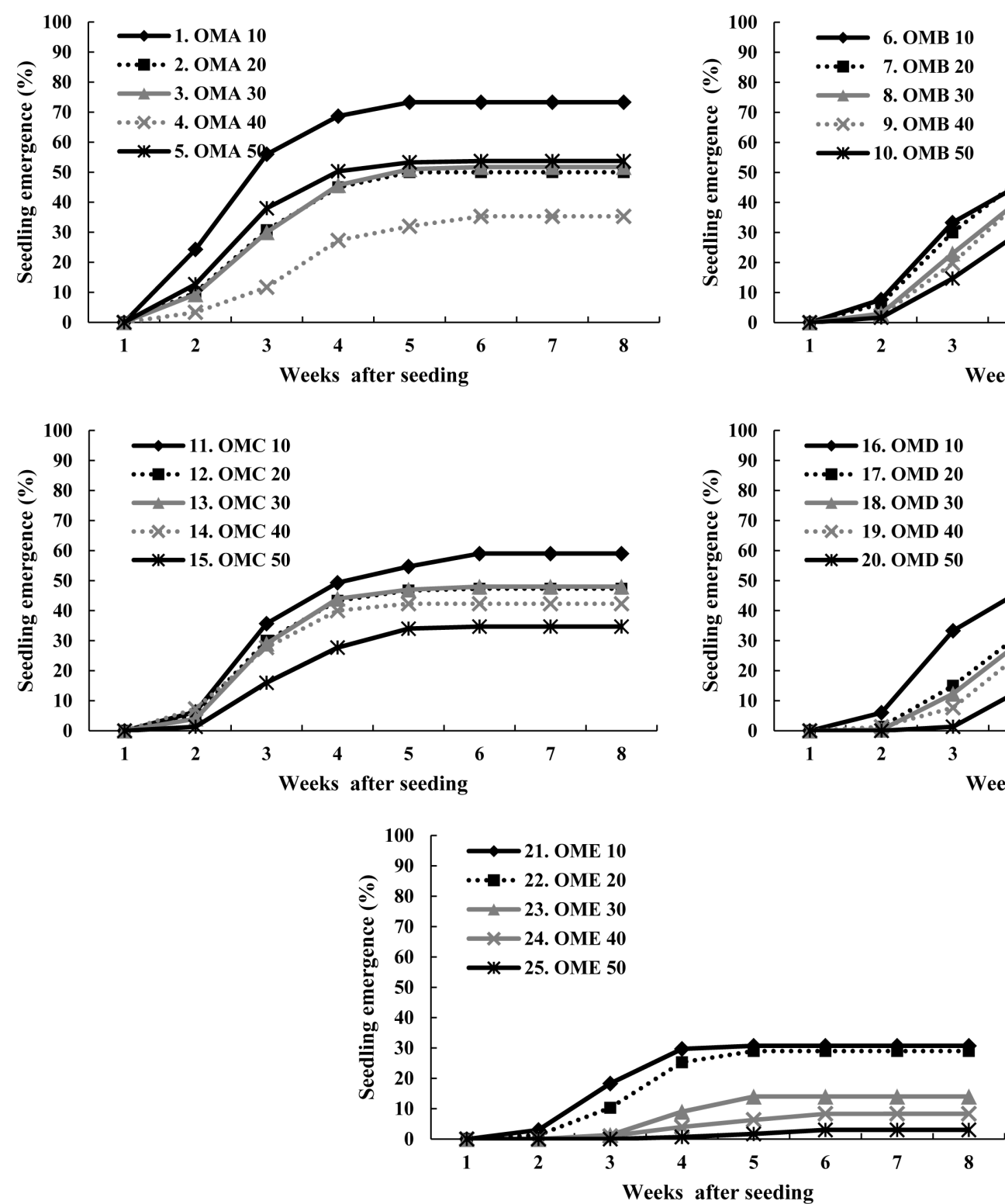

Fig. 2. Cumulative seedling emergence of Kentucky bluegrass which was grown under greenhouse conditions. Treatments were comprised of five organic matter amendments and sand. The amendments were OMA (Berger Peat, Les Tourbières Berger Ltee, Quebec, Canada), OMB (Eco-Peat, Nature \& Environment Co., Ltd., Seoul, Korea), OMC (G1-Soil, Nature \& Environment Co., Ltd., Seoul, Korea), OMD (Premier Peat, Premier Tech Horticulture, Quebec, Canada), and OME (Supersoil I, Jookjoo Fertilizers, Iljuk, Kyounggi, Korea). A total of 25 treatments were arranged with these amendments at five volume percentages (10, 20, 30, 40 and 50\%; v/v) as described in Table 2. The remaining soil for each treatment was a pure silica sand meeting USGA putting green specifications. concluded by researchers (Glasgow et al., 2005; Magni et al., 2005) that composted organic materials are beneficial in turf establishment by increasing water holding capacity and nutrient retention. A reason for this is that hydrophilic nature can explain the greater water retention from the compost-amended soil (Magni et al., 2005). Bethke (1988), however, reported that excessive peat caused chemical and
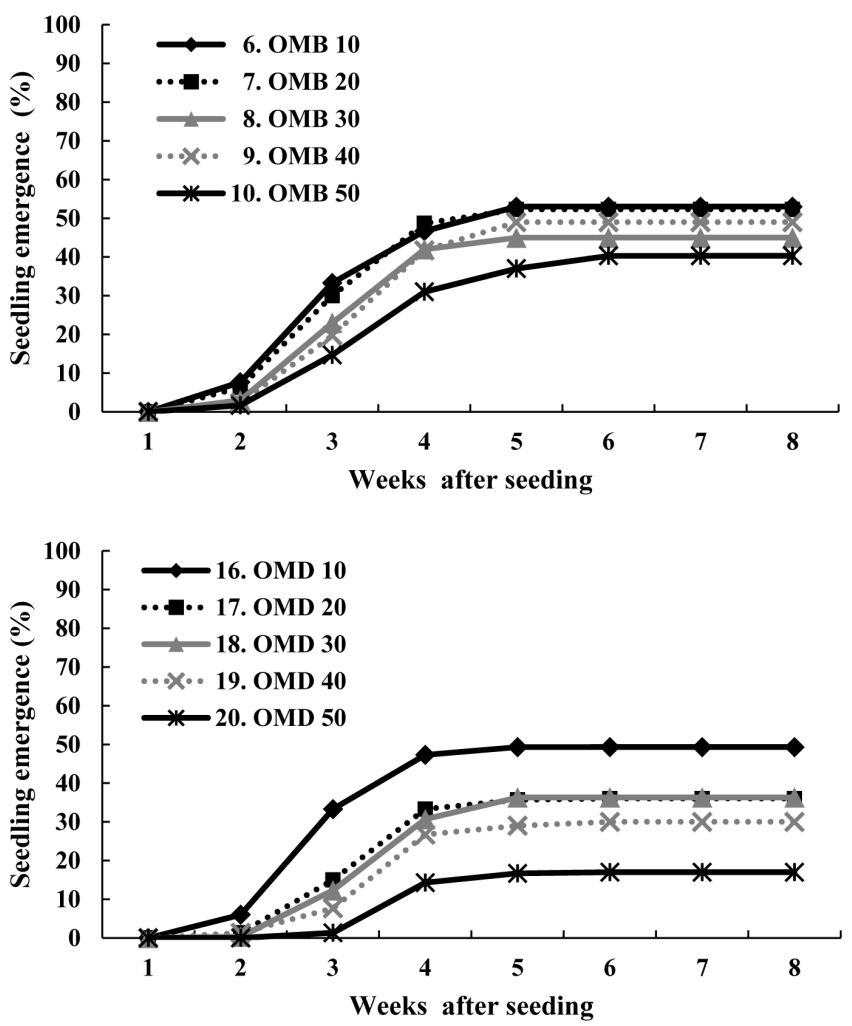
physical properties of rootzone mix to be a poor turf growth. Organic matter in rootzone exceeding a certain level can cause blockage of macropores to deteriorate some physical properties such as drainage, aeration, and water retention. This turns to increased disease and reduced rooting (Adams and Saxon, 1979). During the study we observed some disease occurrence in higher-mixed plots of 40 to $50 \%$ of OSAs.

\section{Top Growth}

Significant differences were found in top growth according to the type of OSAs and their rates. There were considerable variations of $\mathrm{KB}$ shoot growth, being 3.8 to $14.5 \mathrm{~cm}$ (Fig. 3). The OMA mixtures ranged between 4.5 and $6.5 \mathrm{~cm}$ in plant height. In general, the higher the OMA rate, the longer the plant height. Accordingly, plots over OMA 30 had a longer shoot growth, resulting in 6.0 to $6.5 \mathrm{~cm}$ of height. The shortest growth was associated with OMA 10, being $4.5 \mathrm{~cm}$. Plots mixed with OMB produced 4.6 to 5.8 $\mathrm{cm}$ in plant height. The highest growth of $5.8 \mathrm{~cm}$ was associated with OMB 40. The second height was $5.3 \mathrm{~cm}$ in plots of OMB 50.

Evaluation on the OMC mixtures showed that plant height ranged between 4 and $5 \mathrm{~cm}$. The greatest height of 4.6 $\mathrm{cm}$ was observed from plots in OMC 20. But the shortest was $4.0 \mathrm{~cm}$ from both $\mathrm{OMC} 10$ and 50 mixtures. Plots amended with OMD showed 3.8 to $4.8 \mathrm{~cm}$ in plant height. The highest height of $4.8 \mathrm{~cm}$ was associated with OMD 40. But the lowest was from plots in OMD 50, being 3.8 $\mathrm{cm}$ of plant height. From the OME plots it was greatly variable from 7.8 to $14.5 \mathrm{~cm}$. The OME 30 mixture had the greatest height of $14.5 \mathrm{~cm}$. The second greatest value was $12.0 \mathrm{~cm}$ from OME 40 . But the shortest was $7.8 \mathrm{~cm}$, being observed with OME 10 .

This study showed that KB top growth was greatly variable with OSAs and their rate. In general, optimum rates were considered as 20 to $40 \%$ for a vigorous shoot growth. Among five OSAs evaluated, there was a little difference in shoot growth with an exception of OME amendment, which resulted in much more shoot growth than others.

As a rhizomatous-type of growth habit, $\mathrm{KB}$ is more prone to horizontal growth (Beard and Beard, 2005; Turgeon, 2005), being shorter in plant height as compared with bunch-type turfgrass such as perennial ryegrass and tall fescue (Festuca arundinacea Schreb.). This study, however, demonstrated that shoot growth orientation is also influenced by OSAs in KB. In other words, it might grow more vertically depending on the kind of OSAs used. Consequently, it is practically necessary to consider a specific OSA for a turf

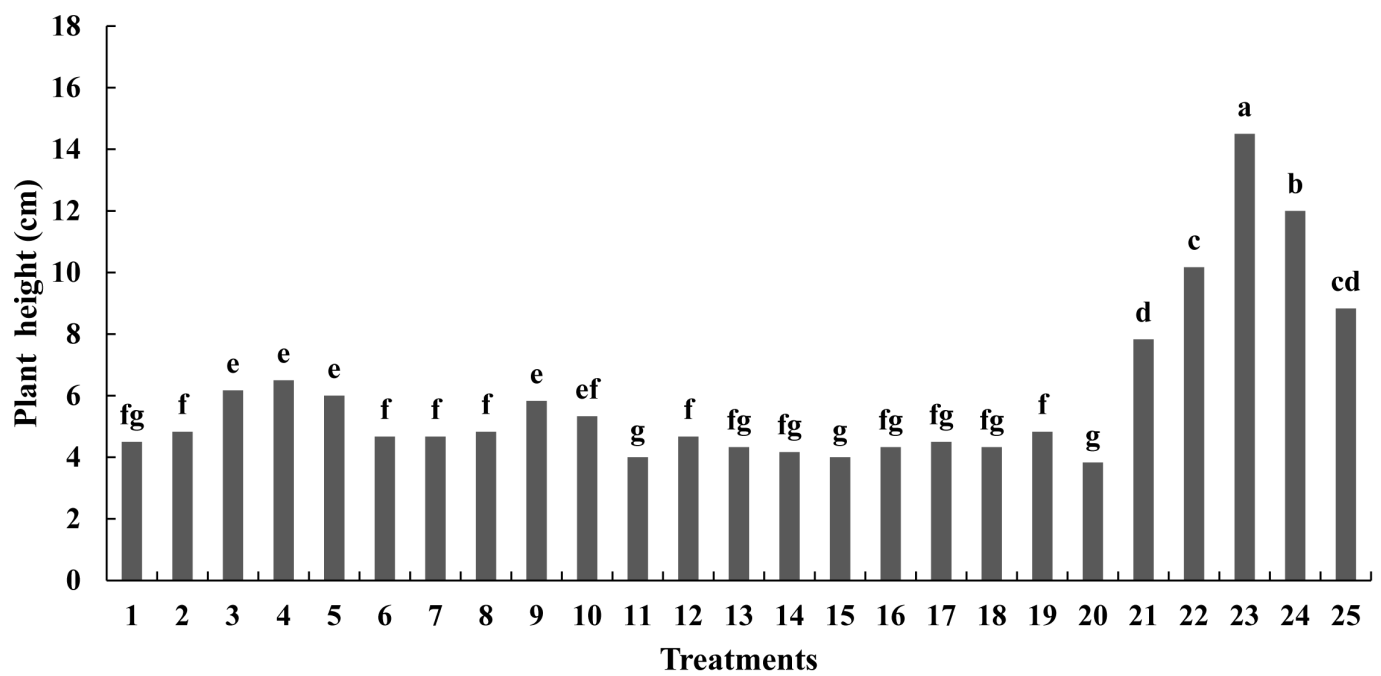

Fig. 3. Plant height of Kentucky bluegrass at the end of study which was grown under greenhouse conditions. Treatments were comprised of five organic matter amendments and sand. The amendments were OMA (Berger Peat, Les Tourbières Berger Ltee, Quebec, Canada), OMB (Eco-Peat, Nature \& Environment Co., Ltd., Seoul, Korea), OMC (G1-Soil, Nature \& Environment Co., Ltd., Seoul, Korea), OMD (Premier Peat, Premier Tech Horticulture, Quebec, Canada), and OME (Supersoil I, Jookjoo Fertilizers, Iljuk, Kyounggi, Korea). A total of 25 treatments were arranged with these amendments at five volume percentages (10, 20, 30, 40 and 50\%; v/v) as described in Table 2. The remaining soil for each treatment was a pure silica sand meeting USGA putting green specifications. Bars with different letters are significantly different based on Duncan's multiple range test at $P=0.05$. 
Table 4. Summary of overall performance and optimum rate for rootzone mix on the growth characteristics by organic soil amendment (OSA) in Kentucky bluegrass in the study.

\begin{tabular}{|c|c|c|c|c|c|c|}
\hline \multirow{2}{*}{$\begin{array}{l}\text { Organic soil } \\
\text { amendment }^{2}\end{array}$} & \multicolumn{4}{|c|}{ OSA performance ${ }^{\mathrm{y}}$} & \multicolumn{2}{|c|}{ Optimum OSA rates $(\%, v / v)$} \\
\hline & $\begin{array}{c}\text { Establishment } \\
\text { vigor }\end{array}$ & $\begin{array}{l}\text { Shoot } \\
\text { growth }\end{array}$ & $\begin{array}{l}\text { Overall } \\
\text { rating }\end{array}$ & $\begin{array}{l}\text { Suggested intensity } \\
\text { for maintenance }\end{array}$ & $\begin{array}{l}\text { Establishment } \\
\text { vigor }\end{array}$ & $\begin{array}{l}\text { Shoot } \\
\text { growth }\end{array}$ \\
\hline OMA & +++++ & ++ & +++ & medium & 10 & $30-50$ \\
\hline OMB & +++ & ++ & ++ & low & $10-20$ & 40 \\
\hline $\mathrm{OMC}$ & ++++ & + & +++++ & high & 10 & 20 \\
\hline OMD & +++ & + & ++++ & high & 10 & 40 \\
\hline OME & + & +++++ & + & very low & $10-20$ & $30-40$ \\
\hline
\end{tabular}

${ }^{\mathrm{z} O S A}$, organic soil amendment; OMA, Berger Peat (Les Tourbières Berger Ltee, Quebec, Canada); OMB, Eco-Peat (Nature \& Environment Co., Ltd., Seoul, Korea); OMC: G1-Soil (Nature \& Environment Co., Ltd., Seoul, Korea); OMD, Premier Peat (Premier Tech Horticulture, Quebec, Canada); OME: Supersoil I (Jookjoo Fertilizers, Iljuk, Kyounggi, Korea).

${ }^{\mathrm{y}}$ OSA performance: $+=$ low; $++=$ low to medium; $+++=$ medium; $++++=$ medium to high; $+++++=$ high .

establishment purpose. For example, increased plant height is more desirable for a rough area in golf course, while lowered plant height much better for a high-density areas such as tees and fairway (Beard, 2004).

At this study the greater shoot growth was not necessarily related with the higher OSA rate. In particular, as for the OMD and OME mixtures, we found that the highest rate of $50 \%$ in mixtures significantly led to a poorer shoot growth. This could be explained by the fact that optimum mixing increases water and nutrient retention, resulting in good growth. But its excessive mixing alters soil physical and chemical balance in rootzone mix leading to poor turf growth. As explained previously, organic matter beyond a certain point can cause macropore blockage to impair drainage, aeration and water retention. In turn it might increase disease and reduce rooting (Adams and Saxon, 1979). Waddington (1992) stated that the soil amendment effect could be varied with mixing rate and method and mixing soil. Bethke (1988) concluded that a general mixing ratio for peat ranged 5 to $20 \%$, but excessive mixing led to poor turf growth by modifying soil physical and chemical properties of rootzone mix.

In this study results demonstrated the differences in establishment vigor, seedling emergence, and top growth according to OSAs and their rates. This conclusion is supported by other researchers. In a study under greenhouse conditions with warm-season turfgrasses, Liu et al. (2005) demonstrated increased clipping yields three times and improved the turf quality in rootzone sand at $15 \%(\mathrm{v} / \mathrm{v})$ with compost organic materials. Also, research with coolseason grass indicated that turf growth and quality were influenced by organic amendment in perennial ryegrass and KB (Kim, 2009a, 2009b).

Optimum rate for rootzone mix may be dependent on the type of OSA. Reasonable mixing rates are considered as 10 to $20 \%$ for establishment vigor and 20 to $40 \%$ for shoot growth, regardless of OSAs (Table 4). Several researchers reported various threshold levels of organic matter in sandbased soil systems. It has been concluded by the same author that proper levels for surface organic matter in rootzone by weight was lower than 3-4\% (Carrow, 1998) and 4-5\% (Carrow, 2004). Adams and Saxon (1979) reported that organic matter levels over $12 \%$ initiated to dominate rootzone performance. But these conclusions for organic matter levels were based on weight basis. The recommendation would be variable when compared with a volumeto-volume basis, being possibly higher rates in mixtures. Alkire (2007) suggested organic matter with $10-20 \%$ of volume should be used to amend the sand content within the sports turf rootzone mix. Therefore, it was considered that its optimum rate varies with OSAs as well as growth characteristics. This means that unknown OSA should be tested for a planting purpose before an on-site application. In a study on the effect of rootzone mixes on the growth of creeping bentgrass (Agrostis palustris Huds.) in putting green (Kim et al., 1999), they concluded that a proper rate for rootzone mix should be decided, based on both turf growth and soil physical properties.

Considering overall responses such as establishment vigor, seedling emergence, and top growth, both local OMC and imported OMD amendments are considered as the useful soil amendments applicable for sports turfs. The amendment OMA is also a good source for rootzone mix. The amendment OME would be applied for a low maintenance turfs such 
as rough and utility areas due to greater shoot growth. Information on these amendments from this study would be of a practical use for sports turf design and construction. A further study would be useful for evaluating OSA effects on growth characteristics of other major turfgrasses. Additional information from repeated experiments and field performance test is also needed for these OSAs to determine proper OSA and rate for sports turf application in Korea as an expensive, importing peat substitute.

\section{Literature Cited}

Adams, W.A. and C. Saxon. 1979. The occurrence and control of thatch in sports turf. Rasen Turf Gazeon 3:76-83.

Alkire, W.K. 2007. Golf course construction principles, p. 3.13-3.27. In: K. Partners (ed.). Integrated golf course management plan for Jack Nicklaus Golf Club-Korea. Golf Ventures International, Incheon, Korea.

Bandaranayake, W., Y.L. Qian, W.J. Parton, D.S. Ojima, and R.F. Follett. 2003. Estimation of soil organic carbon changes in turfgrass systems using the CENTURY model. Agron. J. 95:558-563.

Beard, J.B. 1973. Turfgrass: Science and culture. Prentice-Hall, Englewood Cliffs, NJ, USA.

Beard, J.B. 2004. Turf management for golf course. 2nd ed. Ann Arber Press, MI, USA.

Beard, J.B. and H.J. Beard. 2005. Beard's turfgrass encyclopedia for golf courses, grounds, lawns and sports fields. Michigan State Univ. Press, East Lansing, MI, USA.

Bethke, C.L. 1988. A guide to the selection of peat for use in turf. Golf Course Mgt. 56(3):100-112.

Carrow, R.N. 1998. Organic matter dynamics in the surface zone of a USGA green: Practices to alleviate problems. In: 1998 Turfgrass and Environmental Research Summary. USGA, Far Hills, NJ, USA.

Carrow, R.N. 2004. Surface organic matter in creeping bentgrass greens. Golf Course Mgt. 72(5):96-101.

Choi, B.J., J.S. Shim, and H. Park. 1994. Effect of organic material, active carbon and magnesium on the growth of Zoysia koreana. Kor. J. Turfgrass Sci. 8:193-199.

Cockerham, S.T. 1994. Rootzone mixes, turfgrass selection, and maintenance on the world cup soccer fields in the USA. Proc. Intl. Symp. Soccer Field. Tokyo, Japan, October 27-28, 1994. p. $31-43$.

Garling, D.C. and M.J. Boehm. 2001. Temporal effects of compost and fertilizer applications on nitrogen fertility of golf course turfgrass. Agron. J. 93:548-555.

Glasgow, A., R. Gibbs, K.W. McAuliffe, and C. Liu. 2005. An investigation of organic matter levels in New Zealand greens. Int. Turfgrass Soc. Res. J. 10:1078-1084.

Ham, S.G., S.T. Kim, H.J. Kim, and S.K. Lee. 1997. Effect of IBDU complex and organic fertilizers for creeping bentgrass in golf course. Kor. J. Turfgrass Sci. 11:167-172.

Ham, S.G., J.J. Lee, and I.S. Kim. 1993. Effect of application of organic fertilizer on the growth of Korean lawngrass (Zoysia matrella L. Merr.). Kor. J. Turfgrass Sci. 7:61-66.

Kerek, M. 2003. Labile soil organic matter as a potential nitrogen source in golf greens. Soil Biol. Biochem. 35:1643-1649.

Kim, K.N. 2006. STM Series II: Turfgrass management. Sahmyook Univ. Press, Seoul, Korea.

Kim, K.N. 2007. STM Series III: Turfgrass establishment. Sahmyook Univ. Press, Seoul, Korea.

Kim, K.N. 2009a. Effect of soil organic amendment mixtures with water-absorbing polymer on growth characteristics in perennial ryegrass. J. Nat. Sci. Sahmyook Univ. 44:161-171.

Kim, K.N. 2009b. Effect of soil organic amendment mixtures with water-absorbing polymer on growth characteristics in Poa pratensis L. Kor. J. Turfgrass Sci. 23:317-330.

Kim, K.N. 2011. Effect of high water-absorbing polymer on turfgrass quality of creeping bentgrass, Kentucky bluegrass, and zoysiagrass. Asian J. Turfgrass Sci. 25:59-68.

Kim, K.N. 2012. Effect of polymer, calcium, perlite, and chitosan in soil organic amendment on growth in perennial ryegrass. Asian J. Turfgrass Sci. 26:24-34.

Kim, K.N., J.S. Choi, and S.Y. Nam. 2003. Performance of warmseason and cool-season grass grown in multi-layer, USGA and mono-layer system for athletic fields. J. Kor. Soc. Hort. Sci. 44:539-544.

Kim, K.N., S.G. Koh, Y.S. Kim, S.R. Shim, and H.S. Tae. 1998. A study on the rootzone mix in the multi-layered soil system. 1998 Annual Fall Mtg. Kor. Inst. Landscape Architecture, Yeongnam Univ., Gyeongnam, Korea. p. 34-35.

Kim, K.N., S.Y. Nam, S.K. Koh, and Y.S. Kim. 1999. Effect of root zone mixes on the growth of creeping bentgrass in putting green. 1999 Annual Mtg. ASA-CSSA-SSSA, Salt Lake City, UT, USA. p. 130.

Kim, K.N. and S.H. Park. 2011. Effect of high water-swelling polymer rate on seedling survival of major turfgrass grown on soil organic amendment mixtures. J. Korean Env. Res. Reveg. Tech. 14(2):21-32.

Kim, D.C., J.S. Shim, and W.I. Chung. 1992. The effect of peat and chemical fertilizer application on the growth of Manilagrass (Zoysia matrella Merr.). Kor. J. Turfgrass Sci. 6:83-88.

Koh, S.G., H.S. Tae, and C.H. Ryu. 2006. Effect of animal organic soil amendment on growth of Korean lawngrass and Kentucky bluegrass. Kor. J. Turfgrass Sci. 20:33-40.

Korea Institute of Sport Science (KISS). 1998. Establishment and maintenance of soccer ground. Dongweonsa, Seoul, Korea.

Korean World Cup Organizing Committee (KOWOC). 2000. Guidelines to the establishment and maintenance of the turfgrass ground of 2002 world cup soccer stadium. Kor. Organizing Committee for the 2002 FIFA World Cup-Korea/Japan, Seoul, Korea.

Landshoot, P.J. and A.S. McNitt. 1997. Effects of nitrogen fertilizers on suppression of dollar spots disease of Agrostis stolonifera 
L. Int. Turfgrass Soc. Res. J. 8:905-911.

Lee, S.J. 2003. The effect of KOB-Soil as a soil amendment on turfgrass growth. Kor. J. Turfgrass Sci. 17:13-17.

Li, D., Y.K. Joo, N.E. Christian, and D.D. Miner. 2000. Inorganic soil amendment effects on sand-based sports turf media. Crop Sci. 40:1121-1125.

Liu, L.X, T. Hsiang, K. Carey, and J.L. Eggens. 1995. Microbial populations and suppression of dollar spot disease in creeping bentgrass with inorganic and organic amendments. Plant Dis. 79:144-147.

Liu, H., L.B. McCarty, C.E. Wells, C.M. Baldwin, and P.J. Brown. 2005. A greenhouse establishment study comparing peanut shell bio-solid with peat moss as an organic source for rootzone mix. Int. Turfgrass Soc. Res. J. 10:1108-1114.

Logan, T.J. and B.J. Harrison. 1995. Physical characteristics of alkaline stabilized sewage (N-Viro soil) and their effects on soil physical properties. J. Environ. Qual. 24:153-164.

Lucas, R.E., P.E. Rieke, and R.S. Farnham. 1965. Peats for soil improvement and soil mixes. Michigan State Univ. Ext. Bull. 516.

Magni, S., L. Ruga, M. Gaetani, M. Volterrani, and S. Miele. 2005. Effect of drainage and soil amendment on the quality of horse racecourse turf under simulated use. Int. Turfgrass Soc. Res. J. 10:466-471.

Puhalla, J., J. Krans, and M. Goatley. 2002. Sports fields: A manual for design, construction, and maintenance. Ann Arbor Press, MI, USA.

Puustjarvi, V. and R.A. Robertson. 1975. Physical and chemical properties, p. 23-24. In: D.W Robinson and J.G.D. Lamb (eds.). Peat in horticulture. Kinsealy Research Centre, Agricultural Institute, Dublin, Republic of Ireland.

SAS Inst., Inc. 2001. SAS/STAT user's guide: Statistics version 8.00. SAS Inst., Inc., Cary, NC, USA.

Steel, R.G.D. and J.H. Torrie. 1980. Principles and procedures of statistics. 2nd ed. McGraw-Hill, New York, NY, USA.

The Lawn Institute. 1991. Seed LISTS, p. 69-112. In: E.C. Roberts and B.C. Roberts (eds.). Lawn Institute special topic sheets. Tennessee Cumberland Printing Corp., Crossville, TN, USA.

Turgeon, A.J. 2005. Turfgrass management. 7th ed. Prentice-Hall Inc., Upper Saddle River, NJ, USA.

United States Golf Association (USGA) Green Section Staff. 1973. USGA sections specifications for putting green construction. USGA Green Section Record 11(3):1-8.

Waddington, D.V. 1992. Soils, soil mixtures, and soil amendments, $\mathrm{p}$. 331-384. In: D.V. Waddington, R.N. Carrow, and R.C. Shearman (eds.). Turfgrass. ASA-CSSA-SSSA, Madison, WI, USA.

Waltz, F.C. Jr. and L.B. McCarty. 2005. Field evaluation of soil amendments used in rootzone mixes for golf course putting greens. Int. Turfgrass Soc. Res. J. 10:1150-1158. 